\title{
Phytoalexins: Current and possible future applications in human health and diseases control
}

\begin{abstract}
Plants are prone to diseases and infections following their obvious exposure to microbes and attendant microbial attacks. Plants control diseases and infections by using their secondary metabolites known collectively as phytoalexins. These phytoalexins, usually synthesized in plants in response to diseases and infections, have enormous chemical diversity and biologic roles but are essentially non biodegradable owing to their stable structures hence could bio-accumulate with sustained effect once synthesized. Thus, this reviewed current and possible future applications of phytoalexins in human health and diseases control using relevant search words and search engines. The review noted that resveratrol, a representative of, and an extensively studied, phytoalexins was variously implicated in the management of human health, including in the prevention of cardiovascular disease and cancers. Resveratrol acts via mechanisms essentially related to its capacity to ameliorate oxidative stress perhaps by significantly enhancing the synthesis of nitric oxide, NO, which could act as an antioxidant. Increased oxidative stress has been implicated in human diseases and efforts aimed at mitigating (or preventing the onset of) oxidative stress have been the underlying approach to human disease management and control. Thus, the current applications of phytoalexins as shown by resveratrol could be extended to other human health and diseases, warranting detailed empirical studies.
\end{abstract}

Keywords: phytoalexins, resveratrol, bioaccumulation, cardio-protective, cardiomycetes
Volume 3 Issue 3 - 2018

\author{
Anthony Cemaluk C Egbuonu,' Juliet C \\ Eneogwe ${ }^{2}$ \\ 'Department of Biochemistry, Michael Okpara University of \\ Agriculture, Nigeria \\ ${ }^{2}$ Department of Biochemistry, Michael Okpara University of \\ Agriculture, Nigeria
}

Correspondence: Anthony Cemaluk C Egbuonu, Department of Biochemistry, Michael Okpara University of Agriculture, Umudike, Abia State, Nigeria, Tel +23480.3636-6565,

Email tonycemalukegbuonu@yahoo.com

Received: October 30, 2017| Published: May 10, 2018
Abbreviations: MRSA, methicillin-resistant Staphylococcus aureus; LPS, lipopolysaccharide; TNF- $\alpha$,tumor necrotic factoralpha; NO, nitric oxide; ROS, reactive oxygen species; NADPH, nicotinamide adenine dinucleotide phosphate.

\section{Introduction}

Plants are prone to diseases and infections following their obvious exposure to microbes and attendant microbial attacks. Plants, therefore, accumulate an armory of anti microbial secondary metabolites which they use for protection against pathogenic microorganisms and for controlling resultant diseases and infections. Those anti microbial secondary metabolites are known collectively as phytoalexins. Phytoalexins are antimicrobial compounds. ${ }^{1}$ Phytoalexins are a group of photochemical of low molecular weight which inhibit microorganis$\mathrm{ms}$ and accumulate in plants following interaction of the plant with microorganisms. ${ }^{2}$ The production of phytoalexins in the plant once the pathogen has been detected involves induced response mechanism resulting in the secretion of the antimicrobial compounds to the infected sites. ${ }^{3}$ Thus, phytoalexins can aside acting as plant, could act as human, disease controlling antimicrobial agents. For example, hydroxycoumarin scopoletin (6-methoxy-7-hydroxycoumarin), a major phytoalexins in tobacco plants, displays antimicrobial activity. ${ }^{4-6}$ It elicited scavenging activity over reactive oxygen specie. ${ }^{7}$ They are essentially non biodegradable owing to their stable structures hence could bio-accumulate with sustained effect once synthesized. Thus, plants have always been good direct and indirect sources of drugs, including many of the currently available drugs. For instance, a wide array of plant derived active principles representing numerous chemical compounds has demonstrated activity consistent with their possi- ble use in the treatment of diabetes mellitus. ${ }^{8}$ Many plant associated microbes are pathogens that affect plant overall physiology and health status of living things. Phytoalexins represent constitutive chemical barriers to microbial attacks which are usually activated either prior to or on recognition of pathogen elicitors. ${ }^{9}$ Thus, this reviewed current and possible future applications of phytoalexins in human health and diseases control.

The chemical diversity and biologic roles of phytoalexins are enormous. The diversity perhaps derives from their varied plant sources. Thus, to achieve the review aim, resveratrol - a representative of, and an extensively studied, phytoalexins was studied. Resveratrol was variously implicated in the management of human health, including in the prevention of cardiovascular disease and cancers. Resveratrol acts via mechanisms essentially related to its capacity to ameliorate oxidative stress perhaps by significantly enhancing the synthesis of nitric oxide, NO, which could act as an antioxidant. Increased oxidative stress has been implicated in human diseases and efforts aimed at mitigating (or preventing the onset of) oxidative stress have been the underlying approach to human disease management and control. This review could provide update on the current applications of phytoalexins as shown by resveratrol and in addition provide deep insight on possible future application of phytoalexins in human health and diseases control that could provoke detailed empirical studies.

\section{Methods}

In this review, conventional search engines, including Google and relevant search words were used. In particular, current and possible future applications of phytoalexins in human health and diseases control were highlighted. 
Current and possible future applications of Phytoalexins in human health and diseases control

\section{Phytoalexins as antimicrobial agents}

Phytoalexins are antimicrobials ${ }^{1}$ and accumulate in plants to inhibit microorganisms following interaction of the plant with pathogenic microorganisms. ${ }^{2}$ Phytoalexins production by plants following detection of pathogens (an induced response mechanism) results in the secretion of the potent antimicrobials to the infected sites. ${ }^{3}$ The antimicrobial potentials of phytoalexins could be exploited in managing human diseases caused be microbes. For example, Hydroxycoumarin scopoletin(6-methoxy-7-hydroxycoumarin), which represents major phytoalexins in tobacco plants, elicited antimicrobial activity $^{4-6}$ and in rats even improved serum bio-indicators of varied organs functions in rats. ${ }^{10-12}$ Currently, phytoalexins are utilized as antibiotic potentiators. ${ }^{13,14}$ A good example is epigallocatechingallate which potentiated the activity of $\beta$-lactam antibiotics against methicillin-resistant Staphylococcus aureus (MRSA) by mechanisms involving binding of the catechin in the bacterial wall. ${ }^{15}$ Phytoalexins from garlic extract and from cranberry fruit exhibited antimicrobial properties against many pathogens. ${ }^{16}$ Other antimicrobial activities mediated by various phytoalexins have been documented. ${ }^{17-19}$

\section{Phytoalexin as anti inflammatory, antitumor and anticancer agents}

Phytoalexins act as anti-inflammatory agent via poorly characterized mechanism that involves the prevention of the expression of inducible nitric oxide syntheses (NOS) which is involved in the production of a high concentration of NO by inducible NOS in inflammation..$^{20}$ Resveratrol, the most studied phytoalexins, inhibited the inflammatory response of even colon cancer cell lines induced by lip polysaccharide (LPS) by inhibiting the signaling pathway possibly related to a direct action on the nuclear transcription factor via phosphorylation inhibition $^{21}$ or by reversal of the level and expression of, for instance, hepatic tumor necrotic factor-alpha, TNF- $\alpha . .^{22,23}$ Cancer is a multistep disease characterized by uncontrolled cell growth, acquisition of metastatic properties and complex communications between intricate signaling networks. ${ }^{24,25}$ Phytoalexins could suppress tumor progression to cancer since inflammation-mediated processes, including the production of cytokines, chemokines, and reactive oxygen and nitrogen species may contribute to malignant cell transformation. ${ }^{26,27}$ In essence, phytoalexins could control the initiation and progression of cancer by way of their anti inflammatory activities. Resveratrol inhibited the inflammatory response of colon cancer cell lines. ${ }^{21}$ Synthesized substituted resveratrol analogs exhibited more potent anti-tumor and anti-inflammatory effects. ${ }^{28}$

\section{Phytoalexin as anti hyperglycemic agent}

The patho-physiological mechanisms leading to hyperglycemia and eventually to diabetes involve an inappropriate secretion of insulin or insulin resistance or both. ${ }^{29}$ Hyperglycemia can result to or from reduced number of glucose transporters, down regulation in the number of insulin receptors as well as defects of tissue insulin signal transduction. And, eventually to absolute increase in hepatic glucose output exceeding glucose utilization and protein wasting due to the unavailability of carbohydrates for energy metabolism. ${ }^{30,31}$ These series of metabolic evens were improved following resveratrol exposure to diabetic rats, suggesting that resveratrol could induce blood glucose homeostasis to prevent hyperglycemia. ${ }^{32}$ Persistent hyperglycemia resulting in glycation of hemoglobin (formation of glycosylated hemoglobin) hence decreased level of hemoglobin in diabetic patients was restored, though in diabetic rats treated with resveratrol and glyclazide for 30 days. ${ }^{33}$

\section{Phytoalexin as anti-apoptotic and cardio protective agents}

Increased myocardial cell apoptosis, ${ }^{34}$ mitochondrial dysfunction ${ }^{35}$ and caspase-independent apoptosis pathway ${ }^{36}$ were involved in the mediation of cardio-toxicity. Evidence abound that resveratrol could act as an anti-apoptotic agent to provide cardio-protection through inhibition of caspase- 3 expression and activity. ${ }^{37,38}$ Previous study showed that cardiotocic effects of injection of doxorubicin, a cardio-toxic agent, were ameliorated on concomitant administration/ injection with resveratrol. ${ }^{35,39-41}$ The apparent benefit of resveratrol in the prevention of cardiovascular disease ${ }^{41}$ as well as other significant health conditions including protection against cancers ${ }^{42}$ obesity, diabetes, ${ }^{43}$ neurodegenerative diseases ${ }^{44}$ supports important future applications of phytoalexins in human diseases control.

\section{Phytoalexin in oxidative stress}

Interestingly, chronic administration of resveratrol protected a variety of tissues against ischemic injury by reducing the free radical production. ${ }^{45,46}$ The reduction of free radicals by resveratrol could protect neurons which are vulnerable to the reactive oxygen species generated by ischemia-reperfusion. ${ }^{47,48}$ Resveratrol administration in rats significantly increased the hippocampal NO (nitric oxide) production resulting to increased cerebral blood flow to protect animal from ischemia-induced neuron loss ${ }^{49}$ Nitric oxide is a vascular dilator, hence could on dilation of the arterial wall increase the arterial volume while reducing the arterial pressure based on the Boyle's law. Evidence abound suggesting that increased oxidative stress with increased free radical production and decreased myocardial endogenous antioxidants play an important role in the pathogenesis of cardio-toxicity. ${ }^{50-52}$ Phytoalexins elicited scavenging activity over reactive oxygen specie. ${ }^{7}$ Resveratrol treatment prevented the severity of doxorubicininduced cardio-toxicity by alleviating the extent of oxidative stress ${ }^{50}$ as demonstrated by increased levels of superoxide dismutase (SOD) and decreased levels of malondialdehyde. ${ }^{37}$ Possible mechanisms for resveratrol-induced antioxidant activities have been elucidated and involve among others the reduction of basal ROS (reactive oxygen species) generation, subsequent polarization of mitochondrial membrane potential ${ }^{52,53}$ and by inhibition of nicotinamide adenine dinucleotide phosphate (NADPH) or attenuating cellular oxidative stress. ${ }^{54}$ The possible application of phytoalexins, notably resveratrol in combating oxidative stress is will have significant impact in human diseases and control as oxidative stress is fundamental to many diseased conditions. ${ }^{55-57}$ Thus detailed research studies in this area are warranted and recommended. Further evidence abound that the most studied phytoalexins, resveratrol (3,5,4'-trihydroxystilbene), interacted with molecular targets affecting apoptosis, including protein kinases and transcription factors to increase apoptosis ${ }^{58-62}$ and, possible mechanisms of resveratrol actions have been documented including prevention of mutagenesis and even inhibition of DNA synthesis. ${ }^{63-71}$

\section{Chemical diversity of phytoalexins}

Phytoalexins are not restricted to resveratrol. Diverse chemically active phytoalexins exit that belong to various families, including 
phenolics, terpenoids, furanoacetylenes, steroid glycoalkaloids, indoles, ${ }^{72-74}$ and as resveratrol, have wide application in human health and disease. The chemical diversity of phytoalexins, their plant family source (and reported role in human health and diseases) are as surmised in (Table 1). ${ }^{72,75-78}$

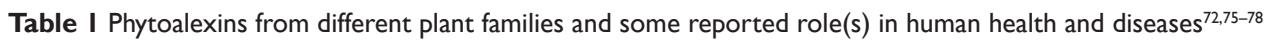

\begin{tabular}{|c|c|c|c|}
\hline $\mathbf{S} / \mathbf{N}$ & Phytoalexins & Plant family & Role(s) in human health and diseases \\
\hline $\mathrm{I}$ & Resveratrol (Stilbenes) & Vitaceae (grapevine) & $\begin{array}{l}\text { anti-oxidant, anti carcinogenic/antiproliferative agent } \\
\text { exerting antitumor activity either as a cytostatic or a } \\
\text { cytotoxic agent in various cancers }\end{array}$ \\
\hline 2 & Flavans & Amaryllidaceae & - \\
\hline 3 & Camalexin (Indole); Brassinin (sulphur containing) & Brassicaceae & $\begin{array}{l}\text { antiproliferative activities in human colorectal cancer cells } \\
\text { in vitro, Induction of apoptosis in prostate cancer cells }\end{array}$ \\
\hline 6 & Casbene (Diterpenes) & Euphorbiaceae & - \\
\hline 7 & Ipomeamarone (Furanosesquit-erpenes) & Convolvulaceae & - \\
\hline 8 & Terpenoids; gossypol (naphtaldehydes) & Malvaceae & - \\
\hline 9 & Isoflavones; Isoflavanones; Coumestans (Isoflavans) & Leguminosae & - \\
\hline II & Moracins A-H (Furanopterocarpans) & Moraceae & - \\
\hline 12 & Loroglossol (Dihydrophenanthrenes) & Orchidaceae & - \\
\hline 13 & Xanthoxylin (Methylated phenolic compounds) & Rutaceae & - \\
\hline 14 & $\begin{array}{l}\text { Falcarinol (Polyacetylenes); Xanthotoxin (Phenolics); } \\
\text { 6-methoxymellein }\end{array}$ & Apiaceae & - \\
\hline 15 & Auarperin (Biphenyls) Cotonefurans (Dibenzofurans) & Rosaceae & - \\
\hline 16 & $\begin{array}{l}\text { Phenylpropanoid related compounds; Steroid } \\
\text { glycoalkaloids ; Norsequi and sesquiterpenoids; } \\
\text { Coumarins; Polyacetylenic derivatives }\end{array}$ & Solanaceae & - \\
\hline 17 & Maslinic acid (Triterpene) & Olives & $\begin{array}{l}\text { Antitumor, antidiabetic, neuroprotective, cardioprotective, } \\
\text { antiparasitic and growth -stimulating agent }\end{array}$ \\
\hline 19 & Indoles and stilbenes & - & Cardioprotective activity \\
\hline 20 & Steroid glycoalkaloids & potato & Varied level of toxicity in humans \\
\hline 21 & Dimeric sesquiterpene gossypol & cotton & Varied level of toxicity in humans \\
\hline
\end{tabular}

\section{Conclusion}

Phytoalexins are essentially non biodegradable owing to their stable structures hence could bio-accumulate with sustained effect once synthesized. Phytoalexins synthesized and usually released by plants in response to diseases and infections have ameliorative potential on diabetes mellitus, ischemia, cardiomyocytes apoptosis, cancer, tumor, microbial pathogens, hyperglycemia and oxidative stress, hence could be beneficial in human diseases control. These effects were enormous owing to the chemical diversity of phytoalexins from varied plant sources and were in this review substantiated using resveratrol, a representative of, and an extensively studied, phytoalexins via mechanisms essentially related to their capacity to ameliorate oxidative stress that involve among other enhancing the synthesis of nitric oxide, NO, which could act as an antioxidant and as a vascular dilator. In particular, increased oxidative stress has been implicated in human diseases and efforts aimed at mitigating (or preventing the onset of) oxidative stress have been the underlying approach to human disease management and control. Thus, the current applications of phytoalexins as shown by resveratrol could be extended to other human health and diseases, warranting detailed empirical studies.

\section{Acknowledgements}

None.

\section{Conflict of interest}

The author declares no conflict of interest.

\section{References}

1. Grayer RJ, Kokubun T. Plant-fungal interaction: the search for phytoalexins and other antifungal compounds from higher plants. Phytochemistry. 2001;56(3):253-263.

2. Bavaresco L. Role of viticultural factors on stilbene concentrations of grapes and wine. Drugs Exp Clin Res. 2003;29(5-6):181-187. 
3. Bednarek P, Osbourn A. A plant-microbe interactions: chemical diversity in plants defense. Science. 2009;324(5928):746-748.

4. Valle T, Lopez JL, Hernandez JM, et al. Antifungal activity of scopoletin and its differential accumulation in Ulmus Campestris cell suspension cultures infected with Ophiostoma ulmi spores. Plant science. 1997;225(1):97-101.

5. Chong J, Baltz R, Schmitt C, et al. Down regulation of pathogenresponsive tobacco UDP-Glc. phenylpropanoidglucosyl tranferase reductasescopoletin glucoside accumulation, enhances oxidative stress and weakens virus resistance. Plant cell. 2002;14(5):1093-1107.

6. Matros M, Mock HP. Ectopic expression of a UDP-Glucose Phenylpropanoidglucosyl tranferase reductasescopoletin glucoside leaded resistance of transgenic tobacco plant against infection with potato virus. Plant cell physiol. 2004;45(9):1185-1193.

7. Chong J, Baltz R, Fritig B, et al. An early salicitic acid -pathogenand-elicitors- inducible tobacco glycosyltransferase: roles in compartmentization of phenolics and $\mathrm{H}_{2} \mathrm{O}_{2}$ metabolism. FEBS Lett. 1999;458(2):204-208.

8. Witters LA. The blooming of the French lilac. $J$ Clin Invest. 2001;108(8):1105-1107.

9. Jones JD, Dang JL. The plant immune system. Nature. 2006;444:323329.

10. Egbuonu ACC, Ogbu AE, Ezeanyika LUS. Sub-chronic oral esculetin (6,7-dihydroxy-coumarin) exposure in male Wistar rats: Effect on some serum functions and organ histology. Asian Journal of Biochemistry. 2015;10(2):67-77.

11. Egbuonu ACC, Ogbu AE, Ijeh II, Ezeanyika LUS. Sub-chronic esculetin (6,7-dihydroxy-coumarin)-induced alteration in some haematological and serum parameters in normal male Wistar rats. Asian Journal of Biochemistry. 2015;10(6):306-311.

12. Egbuonu ACC, Ogbu AE, Ezeanyika LUS. Dose-related influence of esculetin (6,7-dihydroxy-coumarin) on some liver and prostate function markers of male Wistar rats. Journal of Biological Sciences. 2012;12(4):253-257

13. Shah PM. The need for new therapeutic agents: What is in the pipeline? Clin Microbiol Infect. 2005;11(3):36-42.

14. Talbot GH, Bradley J, Edwards JE, et al. Bad bugs need drugs: An update on the development pipeline from the antimicrobial availability task force of the infectious diseases society of America. Clin Infect Dis. 2006;42(5):657-668

15. Zhao WH, Hu ZQ, Okubo S, et al. Mechanism of synergy between epigallocatechin gallate and $\beta$-lactams against methicillinresistant Staphylococcus aureus. Antimicrob Agents Chemother. 2001;45(6):1737-1742.

16. Puupponen Pimiä R, Nohynek L, Alakomi HL, et al. Bioactive berry compounds-Novel tools against human pathogens. Appl Microbiol Biotechnol. 2005;67(1):8-18

17. Moisan H, Brouillette E, Jacob CL, et al. The transcription of virulence factors in Staphylococcus aureus small colony variants isolated from cystic fibrosis patients is influenced by SigB. $J$ Bacteriol. 2006;188(1):64-76.

18. Mitchell G, Lamontagne CA, Brouillette É, et al. Staphylococcus aureus SigB activity promotes a strong fibronectin-bacterium interaction which may sustain host tissue colonization by smallcolony variants isolated from cystic fibrosis patients. Mol Microbiol. 2008;70(6): 1540-1555.

19. Mitchell G, Gattuso M, Bouarab K, et al. Tomatidine affects virulence regulators of prototypical Staphylococcus aureus and small colony variants of cystic fibrosis patients. USA: SanFrancisco: ICAAC; 2009:1-1341.

20. Kowluru RA, Abbas SN, Odenbach S. Resveratrol of hyperglycemic and diabetic nephropathy: effects of reinstitution of metabolic control on oxidative stress in the kidney of the diabetic rats. $J$ Diabetes Complication. 2004;18(5):282-288.

21. Panaro MA, Carofiglio V, Acquafredda A, et al. Anti-inflammatory effects of resveratrol occur via inhibition of lipopolysaccharideinduced NF-kB activation in Caco-2 and SW480 human colon cancercells. Br J Nutr. 2012;108(9):1623-1632.

22. Mbimba $\mathrm{T}$, Awale $\mathrm{P}$, Bhatia $\mathrm{D}$, et al. Alteration of hepatic proinflammatory cytokines is involved in the resveratrolmediated chemoprevention of chemically-induced hepatocarcinogenesis. Curr Pharm Biotechnol. 2012;13(1):229-234.

23. Luther DJ, Ohanyan V, Shamhart PE, et al. Chemopreventive doses of resveratrol do not produce cardiotoxicity in a rodent model of hepatocellular carcinoma. Invest New Drugs. 2011;29(2):380-391.

24. Sarkar S, Horn G, Moulton K, et al. Cancer development, progression, and therapy: an epigenetic overview. Int J Mol Sci. 2013;14(10):2108721113.

25. Shukla Y, Singh R. Resveratrol and cellular mechanisms of cancer prevention. Ann N Y Acad Sci. 2011;1215:1-8.

26. Kundu JK, Surh YJ. Inflammation: gearing the journey to cancer. Mutat Res. 2008;659(1-2):15-30.

27. Allavena P, Germano G, Marchesi F, et al. Chemokines in cancer related inflammation. Exp Cell Res. 2011;317(5):664-673.

28. Szekeres T, Saiko P, Fritzer Szekeres M, et al. Chemopreventive effects of resveratrol and resveratrol derivatives. Ann N Y Acad Sci. 2011;1215:89-95.

29. Mc Carthy MI, Hattersley AT. Molecular diagnostics in monogenic and multifactorial forms of type 2 diabetes. Expert Rev Mol Diagn. 2001;1(4):403-412.

30. Gerich JE. Clinical significance,pathogenesis, and management of postprandial hyperglycemia. Arch Intern Med. 2003;163(11):13061316.

31. Brodsky IG. Nutritional effects of dietary protein restriction in insulindependent diabetes mellitus. $J$ Nutr. 1998;128(2 suppl):S337-339.

32. Palsamy P, Subramanian S. Resveratrol, a natural phytoalexin, normalizes hyperglycemia in streptozotocin-nicotinamide induced experimental diabetic rats. Biomed Pharmacother. 2008;62(9):598605 .

33. Yabe Nishimura C. Aldose reductase in glucose toxicity: a potential target for the prevention of diabetic complications. Pharmacol Rev. 1998;50(1):21-33.

34. Han X, Ren D, Fan P. Protective effects of naringenin-7-O-glucoside on doxorubicin-induced apoptosis in H9C2 cells. Eur J Pharmacol. 2008;581(1-2):47-53.

35. Zhang C, Feng Y, Qu S. Resveratrol attenuates doxorubicininduced cardiomyocyte apoptosis in mice through SIRT1-mediated deacetylation of p53. Cardiovasc Res. 2011;90(3):538-545.

36. Moreira AC, Branco AF, Sampaio SF. Mitochondrial apoptosisinducing factor is involved in doxorubicin-induced toxicity on $\mathrm{H} 9 \mathrm{c} 2$ cardiomyoblasts. Biochim Biophys Acta. 2014;1842(12):2468-2478.

37. Arafa MH, Mohammad NS, Atteia HH, et al. Protective effect of 
resveratrol against doxorubicin-induced cardiac toxicity and fibrosis in male experimental rats. $J$ Physiol Biochem. 2014;70(3):701-711.

38. Usta E, Mustafi M, Walker T, et al. Resveratrol suppresses apoptosis in intact human cardiac tissue - in vitro model simulating extracorporeal circulation. J Cardiovasc Surg. 2011;52(3):399-409.

39. Gu J, Song ZP, Gui DM, et al. Resveratrol attenuates doxorubicininduced cardiomyocyte apoptosis in lymphoma nude mice by heme oxygenase-1 induction. Cardiovasc Toxicol. 2012;12(4):341-349.

40. Sin TK, Tam BT, Yung BY, et al. Resveratrol protects against doxorubicin-induced cardiotoxicity in aged hearts through the SIRT1USP7 axis. J Physiol. 2015;593(8):1887-1899.

41. Bradamante S, Barenghi L, Villa A. Cardiovascular protective effects of resveratrol. Cardiovasc Drug Rev. 2004;22(3):169-188.

42. Hofseth LJ, Singh UP, Singh NP, et al. Taming the beast within: resveratrol suppresses colitis and prevents colon cancer. Aging. 2010;2(4):183-184.

43. Szkudelska K, Szkudelski T. Resveratrol, obesity and diabetes. Eur $J$ Pharmacol. 2010;635(1-3):1-8.

44. Howitz KT, Bitterman KJ, Cohen HY, et al. Small molecule activators of sirtuins extend Saccharomyces cerevisiae lifespan. Nature. 2003;425(6954):191-196.

45. Sinha K, Chaudhary G, Gupta YK. Protective effect of resveratrol against oxidative stress in middle cerebral artery occlusion model of stroke in rats. Life Sci. 2002;71(6):655-665.

46. Wang Q, Xu JF, Rottinghaus GE, et al. Resveratrol protects against global cerebral ischemic injury in gerbils. Brain Res. 2002;958(2):439447.

47. Chan PH. Reactive oxygen radicals in signaling and damage in the ischemia brain. J Cereb Blood Flow Metab. 2001;21(1):2-14.

48. Zini R, Morin C, Bertelli A, et al. Effects of resveratrol on the rat brain respiratory chain. Drug Exp Clin Res. 1999;25(2-3):87-97.

49. Kwok TL, Robin YY, Chiou LGC, et al. Neuroprotective effects of resveratrol on cerebral Ischemia-induced neuron loss mediated by free radical Scavenging and cerebral blood flow elevation. $J$ Agric Food Chem. 2006;54(8):3126-3131.

50. Tatlidede E, Sehirli O, Velio GA. Resveratrol treatment protects against doxorubicin-induced cardiotoxicity by alleviating oxidative damage. Free Radic Res. 2009;43(3):95-205.

51. Singal PK, Iliskovic N, Li T, et al. Adriamycin cardiomyopathy: pathophysiology and prevention. FASEB Journal. 1997;11(12):931936.

52. Danz ED, Skramsted J, Henry N, et al. Resveratrol prevents doxorubicin cardiotoxicity through mitochondrial stabilization and the Sirt1 pathway. Free Radic Biol Med. 2009;46(12):1589-1597.

53. Yu W, Fu YC, Wang W. Cellular and molecular effects of resveratrol in health and disease. $J$ Cell Biochem. 2012;113(3):752-759.

54. Ungvari Z, Bagi Z, Feher A, et al. Resveratrol confers endothelia protection via activation of the antioxidant transcription factor $\mathrm{Nrf} 2$ Am J Physiol Heart Circ Physiol. 2010;299(1):18-24.

55. Egbuonu ACC, Ejike GE. Effect of pulverized Mangifera indica (mango) seed kernel on monosodium glutamate-intoxicated rats' serum antioxidant capacity, brain function and histology. EC Pharmacology and Toxicology. 2017;4(6):228-243.

56. Saurai PF. Silymarin as a natural antioxidant: An overview of the current evidence and perspectives. Antioxidants. 2015;4(1):204-247.
57. Lopez Alarcon C, Denicola A. Evaluating the antioxidant capacity of natural products: A review on chemical and cellular-based assays Analytical Chimica Acta. 2013;763:1-10.

58. Liu BL, Zhang X, Zhang W, et al. New enlightenment of French Paradox: resveratrol's potential for cancer chemoprevention and anticancer therapy. Cancer Biol Ther. 2007;6(12):1833-1836.

59. Sakamoto T, Horiguchi H, Oguma E, et al. Effects of diverse dietary phytoestrogens on cell growth, cell cycle and apoptosis in estrogenreceptor-positive breast cancer cells. J Nutr Biochem. 2010;21(9):856864.

60. Shi Y, Yang S, Troup S, et al. Resveratrol induces apoptosis in breas cancer cells by E2F1-mediated up-regulation of ASPP1. Oncol Rep. 2011; 25(6):1713-1719.

61. Ferruelo A, Romero, Cabrera PM, et al. Effects of resveratrol and other wine polyphenols on the proliferation, apoptosis and androgen receptor expression in LNCaP cells. Actas Urol Esp. 2014;38(6):397-404.

62. Liu B, Zhou Z, Zhou W, et al. Resveratrol inhibits proliferation in human colorectal carcinoma cells by inducing G1/S-phase cell cycle arrest and apoptosis through caspase/cyclin-CDK pathways. Mol Med Rep. 2014;10(4):1697-1702.

63. Shamon LA, Chen C, Mehta RG, et al. A correlative approach for the identification of antimutagens that demonstrate chemopreventive activity. Anticancer Res. 1994;14(5):1775-1778.

64. Prochaska HJ, Santamaria AB. Direct measurement of NAD(P) $\mathrm{H}$ :quinone reductase from cells cultured in microtiter wells: a screening assay for anticarcinogenic enzyme inducers. Anal Biochem. 1988;169(2):328-336.

65. Zhang Y, Kensler TW, Cho CG, et al. Anticarcinogenic activities of sulforaphane and structurally related synthetic norbornyl isothiocyanates. Proc Natl Acad Sci USA. 1994;91(8):3147-3150.

66. Moreno JJ. Resveratrol modulates arachidonic acid release, prostaglandin synthesis, and 3T6 fibroblast growth. J Pharmacol Exp Ther. 2000;294(1):333-338.

67. Tadolini B, Juliano C, Piu L, et al. Resveratrol inhibition of lipid peroxidation. Free Radic Res. 2009;33(200):105-114.

68. Murcia MA, Martinez Tome M. Antioxidant activity of resveratrol compared with commonfood additives. J Food Prot. 2001;64(3):379384

69. Heiss EH, Schilder YD, Dirsch VM. Chronic treatment with resveratrol induces redox stress- and ataxia telangiectasia-mutated (ATM)dependent senescence in p53-positive cancer cells. $J$ Biol Chem. 2007;282(37):26759-26766.

70. Bernhard D, Tinhofer I, Tonko M, et al. Resveratrol causes arrest in the $\mathrm{S}$-phase prior to Fas-independent apoptosis in CEMC7H2 acute leukemia cells. Cell Death Differ. 2000;7(9):834-842.

71. Estrov Z, Shishodia S, Faderl S, et al. Resveratrol blocks interleukin1beta-induced activation of the nuclear transcription factor NFkappaB, inhibits proliferation, causes S-phase arrest, and induces apoptosis of acute myeloid leukemia cells. Blood. 2003;102(3):987995.

72. Suman S. Role of phytoalexins in plant - microbe interactions and human health. Intl J Sci Res \& Mgt (IJSRM). 2017;5(7):6215-6225.

73. Jeandet P. Phytoalexins: Current progress and future prospects Molecules. 2015;20(2):2770-2774.

74. Marcello I, Franco F. Chemical diversity and defence metabolism: how plants cope with pathogens and ozone pollution. Intl J Mol Sci. 2009;10(8):3371-3399. 
75. Jeandet P, Hebrard C, Deville MA, et al. Deciphering the role of phytoalexins in plant - microorganism interactions and human health. Molecules. 2014;19(11):18033-18056.

76. Lozano Mena G, Sanchez Gonzalez M, Juan ME, et al. Maslinic acid, a natural phytoalexin-type triterpene from olives - A promising nutraceutical? Molecules. 2014;19(8):11538-11559.
77. Smith B, Randle D, Mezencev R, et al. Camalexin-induced apoptosis in prostate cancer cells involves alterations of expression and activity of lysosomal protease cathepsin D. Molecules. 2014;19(4):3988-4005.

78. Kello M, Drutovic D, Chripkova M, et al. ROS-dependent antiproliferative effect of brassinin derivative homobrassinin in human colorectal cancer Caco2 cells. Molecules. 2014;19(8):10877-10897. 